\title{
Entoação e ensino de língua
}

\author{
Maíra Sueco Maegava Córdula \\ Universidade Federal do Triângulo Mineiro (UFTM), Uberaba, Minas Gerais, Brasil \\ mcordula@gmail.com
}

DOI: $\underline{\text { http://dx.doi.org/10.21165/el.v45i2.780 }}$

\begin{abstract}
Resumo
O presente trabalho tem por objetivo discutir o lugar da entoação no ensino de português como língua materna, considerando o papel deste elemento prosódico na produção de sentidos do texto oral. Para tanto, discute-se o que é entoação e abordagens de análise desse elemento prosódico em duas vertentes principais: abordagem sistêmico-funcional e abordagem da Fonologia Entoacional Autossegmental-Métrica. Também é realizada uma discussão teórica da relação entre a entoação e o ensino de português, a partir do estudo de documentos de cunho oficial, como os PCN e o PNLD, além de literatura especializada na área. Diante das funções linguísticas da entoação, faz-se necessário desenvolver mais estudos que problematizem a relação entre a descrição e o ensino da variação melódica da fala e sistematizem o tratamento pedagógico a ser dado ao tema.
\end{abstract}

Palavras-chave: entoação; ensino de língua; língua materna; oralidade; ensino fundamental.

\section{Intonation and language teaching}

\begin{abstract}
This paper aims to discuss the role of intonation in teaching of Portuguese as a first language, considering the role of this prosodic aspect in meaning production in oral texts. First of all, the term intonation is discussed together with two different analytical approaches to study this prosodic element: Systemic Functional Theory (SFS) and Intonational Phonology. Besides that, the relationship between intonation and the teaching of Portuguese is discussed, as regards the guidelines proposed in official documents, and specialized literature. In face of the linguistic functions of intonation, there is a demand for more studies that consider the relationship between description and speech melodic variations and its teaching, as well as foundations for the design of systematic and pedagogical treatment of intonation.
\end{abstract}

Keywords : intonation; language teaching; first language; orality, secondary school.

\section{Introdução}

O presente artigo tem por objetivo fazer uma discussão teórica sobre o papel do elemento prosódico da entoação no ensino de língua portuguesa como língua materna. Quando se considera a modalidade oral no ensino de língua portuguesa no ensino regular brasileiro, pouco ainda se vê sobre questões linguísticas da entoação e como ela pode ser trabalhada com os alunos com vistas a contribuir para uma maior desenvoltura na comunicação oral, especialmente em ambientes formais (cf. BRASIL, 2013). Nesse sentido, 
o presente trabalho pretende apresentar o que é a entoação, quais fatores influenciam o seu funcionamento linguístico e como o estudo sistemático desse elemento prosódico pode contribuir para o ensino de língua portuguesa no Brasil como língua materna ${ }^{1}$.

Este trabalho surge de uma proposta mais ampla de analisar o papel da prosódia no ensino de português como língua materna. A partir dessa proposta, foi eleita a entoação como um primeiro elemento a ser analisado, em especial, devido à confusão em que se encontram os dois termos "prosódia" e "entoação" em manuais didáticos ao longo dos tempos. Neste texto, a prosódia engloba aspectos linguísticos que são de esfera suprassegmental, como o ritmo, o acento, a velocidade de fala, etc. A entoação se restringe à variação melódica da fala. Vale ressaltar que um estudo da variação melódica invariavelmente considera outros aspectos prosódicos, devido à natureza do elemento linguístico analisado, mas é importante fazer a distinção entre o que se relaciona mais especificamente às variações entoacionais e a outros aspectos prosódicos.

No tocante ao ensino, é importante ressaltar a ainda ausência de atividades ou pouca sistematização e orientação didática para o desenvolvimento de competência oral no ensino de língua portuguesa em manuais didáticos (BRASIL, 2013, p. 27).

Para realizar a discussão teórica proposta neste artigo, primeiramente apresentamos a entoação e sua caracterização linguística; em seguida, observamos a presença/ausência da oralidade em documentos oficiais de orientação do ensino de língua portuguesa e em materiais didáticos para o ensino de português nas séries finais do Ensino Fundamental.

\section{Entoação: objeto e abordagens de análise linguística}

O estudo de aspectos prosódicos das línguas aguça o interesse de filólogos desde o século XIX, mas já no início dos estudos linguísticos, século $\mathrm{XX}$, a prosódia torna-se parte integrante desta ciência (LEHISTE, 1970, p. 1). A prosódia engloba os elementos considerados acima dos segmentais, como a entoação, o ritmo, a velocidade de fala, o acento, dentre outros.

A entoação, especificamente, refere-se à variação melódica da fala. Em termos acústicos, a entoação é medida em Hertz $(\mathrm{Hz})$ e seu correlato acústico é a frequência fundamental (F0). O correlato perceptivo da entoação é o pitch ou altura melódica, que marca o que é percebido linguisticamente em um ambiente com ruído (para mais detalhes sobre os correlatos acústico e perceptivo da entoação, ver: LADEFOGED, 2006; LAVER, 1994; LEHISTE, 1970).

Os estudos descritivos da entoação a descrevem de duas formas distintas: ou como contornos entoacionais, ou como eventos discretos de variação de altura melódica. A primeira acepção segue a corrente britânica de análise da entoação com expoentes como Palmer (1922), Bolinger (1958), O’Connor e Arnold (1961), Halliday (1970) e Couper-Kuhlen

\footnotetext{
${ }^{1}$ Consideramos, para a discussão neste artigo, o ensino de língua portuguesa como língua materna no Brasil. Salientamos a importância de estudos no ensino de língua portuguesa como língua estrangeira, as sim como segunda língua no Brasil.
} 
(1986). Já a segunda acepção segue a concepção de teóricos americanos, como Pike (1945), Liberman (1975), Pierrehumbert (1980) e Ladd (2008)².

As propostas da corrente britânica têm em comum descrever a entoação a partir de contornos entoacionais. Elas surgiram da necessidade de se estudar a entoação com vistas ao ensino da língua inglesa para falantes estrangeiros, especialmente os trabalhos de O'Connor e Arnold (1961) e de Halliday (1970). A perspectiva sistêmico-funcional de Halliday (1970) embasa estudos atualmente e sua correspondência com a gramática da língua inglesa foi recentemente discutida na publicação de Halliday e Greaves (2008): Intonation and the gramar of English.

A perspectiva de Halliday $\left(2005^{3}\right.$, p. 247$)$ apresenta três pontos principais: tonicidade, tonalidade e tom. A tonicidade se refere à posição da sílaba tônica e aos pés, sendo que apenas uma silaba tônica proeminente pode estar presente em cada unidade tonal, chamada de grupo tonal. A tonalidade tem a ver justamente com a dimensão da unidade em que ocorre o evento tonal, marcando o início e o fim do grupo tonal, a unidade de análise. Por fim, o tom refere-se aos contornos entoacionais distintivos da língua.

Halliday (2005, p. 245) apresenta um conjunto de cinco tons primários simples e dois compostos para a análise da língua inglesa, como demonstra o Quadro 1:

Quadro 1. Sistema de tons primários simples e secundários para o Inglês.

\begin{tabular}{|l|l|l|}
\hline Tom & Movimento tônico & Tendência de término do movimento \\
\hline 1 & descendente & Baixo \\
\hline 2 & $\begin{array}{l}\text { ascendente } \\
\text { descendente-ascendente }\end{array}$ & Alto \\
\hline 3 & ascendente & Médio \\
\hline 4 & (ascendente)-descendente-ascendente & Médio \\
\hline 5 & (descendente)-ascendente-descendente & Baixo \\
\hline 13 & tom 1 mais o tom 3 & Médio \\
\hline 53 & tom 5 mais o tom 3 & Médio \\
\hline
\end{tabular}

Fonte: Córdula (2013, p. 34 adaptado de HALLIDAY, 2005, p. 245)

O conjunto de tons distintivos é produtivo, pois para cada tom é possível relacionar diferentes informações gramaticais e semânticas. Além disso, o uso de um tom não convencional para determinada função sintática pode fornecer informações sobre a atitude do falante perante o conteúdo da proposição ou perante o ouvinte (HALLIDAY; GREAVES, 2008, p. 49-50).

Outra abordagem para a descrição da entoação é baseada em eventos discretos. Pike (1945) considera quatro tons distintos linguisticamente: extremamente alto, alto, médio e baixo, que são numerados de 1 a 4 , respectivamente. A notação proposta inclui informações sobre pausa, acento e ritmo. Os sentidos expressos pelos tons são relacionados à atitude dos falantes (cf. PIKE, 1945, p. 24).

\footnotetext{
${ }^{2}$ A primeira edição deste livro foi publicada em 1996.

${ }^{3}$ Este artigo foi publicado pela primeira vez em 1963.
} 
Atualmente, a Fonologia Entoacional Autossegmental-Métrica (LADD, 2008) utiliza também os eventos tonais discretos como unidade de descrição, a saber: $\mathrm{H}$ (high) e L (low). Os tons também são marcados de acordo com sua posição no alinhamento do texto: acentos tonais $\left(\mathrm{H}^{*} \mathrm{e} \mathrm{L}^{*}\right)$, acentos frasais $(\mathrm{H} \mathrm{e} \mathrm{L})$ e acentos de fronteira $(\mathrm{H} \%$ e $\mathrm{L} \%)$, porém a distribuição em apenas dois tons é inovadora e produtiva (cf. PIERREHUMBERT, 1980). A perspectiva gerativista de análise da Fonologia Entoacional Autossegmental-Métrica estabelece unidades de análise em busca de se relacionar os domínios prosódicos hierarquicamente, com vistas a contribuir para a descrição da gramática da língua. Nesse sentido, as funções sintáticas, semânticas e pragmáticas da entoação não são objeto desta perspectiva teórica.

Observando os dois modelos de análise da entoação apresentados, fica a questão de qual deles é o mais adequado para a situação de ensino de língua, tema deste trabalho. Córdula (2013, p. 270-271), ao realizar um estudo comparativo da entoação em Português Brasileiro e Inglês Norte-americano por meio das duas abordagens apresentadas: abordagem sistêmico-funcional e Fonologia Entoacional Autossegmental-Métrica, ressalta que as duas apresentam aparato teórico para uma discussão dos sentidos produzidos pela entoação, porém destaca:

Em resumo, cada teoria, de acordo com a concepção de língua que a embasa, fornece informações que mais correspondem à sua proposta metodológica. Assim, a abordagem sistêmico-funcional é mais voltada para a relação entre escolhas de variação melódica e suas funções na gramática da língua (sejam elas funções sintáticas ou funções semântico-pragmáticas) e a Fonologia Entoacional AM oferece mais evidências sobre a estrutura interna dos fenômenos fonológicos.

Dessa forma, estudos via uma abordagem sistêmico-funcional da entoação podem contribuir mais rapidamente para se estabelecer as relações entre o elemento prosódico da entoação e suas funções sintáticas, semânticas e pragmáticas. A seguir, discutimos algumas descrições sobre a entoação no Português Brasileiro, de acordo com a Proposta de Halliday $(2005)^{4}$.

Cagliari (1992) faz considerações sobre os elementos prosódicos e suas funções linguísticas. Para tanto, lista os seguintes elementos prosódicos: tons, entoação, tessitura, duração, moras, pausas, tempo, acento, ritmo, volume, registro e qualidade de voz (para uma descrição detalhada dos elementos prosódicos, ver MASSINI-CAGLIARI; CAGLIARI, 2006). As funções linguísticas analisadas são: fonológica, morfológica, sintática, discursiva, dialógica, semântica, pragmática, identificação do falante ou da língua, reestruturação da produção da fala e fonética. Para o autor, a entoação exerce as seguintes funções: sintática (categorias e funções), semântica (conotações e subentendidos) e pragmática (atitudes do falante) (CAGLIARI, 1992, p. 149).

Considerando, então, as funções da entoação na produção textual, nota-se a importância de se apreender seus usos e conhecer as opções de uso disponíveis aos falantes:

\footnotetext{
${ }^{4}$ Para uma breve revisão de descrições recentes do Português Brasileiro, de acordo comas propostas da Fonologia Entoacional Autossegmental-Métrica e da Fonologia Prosódica, ver Córdula (2013, p. 65-78).
} 
Dados os contextos linguísticos e de uso da linguagem, é relativamente fácil prever o valor linguístico dos elementos suprassegmentais prosódicos envolvidos na fala real. Porém, ao organizar o que vai falar, o falante tem diante de si, em geral, várias opções para realizar através destes elementos determinado efeito semântico. Mas também é verdade que há restrições: nem tudo serve para tudo [...]. Na verdade, têm-se muito mais restrições do que liberdade de escolha (CAGLIARI, 1992, p. 149).

Dessa forma, podemos concluir que determinada entoação aplicada à fala explicita determinadas funções linguísticas desempenhadas por esse elemento prosódico em determinado contexto de uso e, devido à produtividade linguística, os padrões entoacionais podem produzir diferentes sentidos em diferentes contextos. Daí a importância de se incluir o estudo sistemático desse aspecto prosódico ao ensino de língua. Manuais de língua estrangeira frequentemente apresentam estudos e práticas sistemáticas sobre a entoação, tanto para a prática de questões sintáticas (declarativas $\mathrm{X}$ interrogativas), quanto de funções semânticas e pragmáticas (polidez, ironia, incerteza, etc.).

Cagliari (20075 , p. 180-184) apresenta algumas funções da entoação para o português brasileiro, listando cerca de 40 exemplos com diferentes nuances de significados. Apesar de todos os falantes terem acesso a essas informações como usuários da língua, a vivência em determinados contextos de uso (alguns espaços públicos e formais não diários) e a prática não voluntária (um contexto formal pode causar desconforto e insegurança na produção linguística, produzindo enunciados mal formados semântica e pragmaticamente) podem produzir nuances de sentido não adequados, por isso a importância da entoação no ensino de língua materna. À guisa de exemplo, podemos dizer que uma fala sem grande variação melódica em uma entrevista de emprego pode soar como se o falante não tenha domínio sobre o que está dizendo, o que pode levar o entrevistador à impressão de que o falante possui pouca articulação e dificuldade de comunicação; ou, outro exemplo, uma alteração de tom crescente de forma rápida e abrupta em um momento de tomada de turno pode soar grosseiro e indelicado; ainda um contorno entoacional crescente-decrescentecrescente versus um crescente-decrescente apontam a diferença entre uma súplica e uma ordem.

Nesta seção, apresentamos o objeto de estudo deste trabalho, a entoação, e algumas abordagens de análise desse elemento prosódico. A partir das observações feitas, nota-se que uma abordagem em que a entoação faz parte da gramática da língua em sua relação com outras esferas, sintáticas, semânticas e pragmáticas - abordagem sistêmico-funcional - pode contribuir melhor para um entendimento de contornos entoacionais significativos e suas funções na produção de sentidos no texto oral. Desse modo, defendemos que se deva conferir espaço ao estudo da entoação no ensino de língua materna. Na próxima seção, discutiremos alguns documentos e literatura especializada sobre o ensino da oralidade em língua portuguesa para traçar uma relação entre a entoação e o ensino de português como língua materna.

\footnotetext{
${ }^{5}$ Esta obra é a tese de livre docência do autor, publicada em 1982.
} 


\section{Entoação e ensino de língua portuguesa}

Após a descrição da entoação e das diferentes formas de abordagem de análise desse elemento linguístico, é necessário falar sobre o papel desse elemento, como um aspecto da oralidade, no ensino de língua materna. Para tanto, nesta seção, faremos uma discussão sobre a oralidade no ensino de língua materna a partir da discussão de alguns documentos oficiais: PCN (BRASIL, 1998) e PNLD (BRASIL, 2013) e de literatura especializada na área.

Considerando os Parâmetros Curriculares Nacionais como documentos oficiais orientadores do trabalho docente, é importante verificar como a oralidade e, em especial, a entoação é considerada dentro de um plano de ensino de língua materna no ensino fundamental. A seguir, apontamos os aspectos considerados pelos Parâmetros Curriculares Nacionais para o ensino de língua portuguesa para os terceiros e quarto ciclos do ensino fundamental.

Os PCN (BRASIL, 1998), além de outros temas, discorrem sobre os conteúdos e sobre os princípios e orientações para as práticas de escuta e de produção de textos orais. Quando descreve o texto oral, o documento reconhece o já desenvolvimento do aluno nessa modalidade da língua em seu uso diário e a presença constante da mesma na sala de aula, porém destaca que apenas a interlocução em sala de aula não é o suficiente para desenvolver habilidades importantes para a vida do aluno em situações públicas:

No entanto, nas inúmeras situações sociais do exercício da cidadania que se colocam fora dos muros da escola - a busca de serviços, as tarefas profissionais, os encontros institucionalizados, a defesa de seus direitos e opiniões - os alunos serão avaliados (em outros termos, aceitos ou discriminados) à medida que forem capazes de responder a diferentes exigências de fala e de adequação às características próprias de diferentes gêneros do oral. Reduzir o tratamento da modalidade oral da linguagem a uma abordagem instrumental é insuficiente [...] (BRASIL, 1998, p. 25).

Além disso, o documento ressalta:

Dessa forma, cabe à escola ensinar o aluno a utilizar a linguagem oral no planeja mento e realização de apresentações públicas: realização de entrevistas, debates, seminários, apresentações teatrais etc. Trata-se de propor situações didáticas nas quais essas atividades façam sentido de fato, pois é descabido treinar um nível mais formal da fala, tomado como mais apropriado para todas as situações. A aprendizagem de procedimentos apropriados de fala e de escuta, em contextos públicos, dificilmente ocorrerá se a escola não tomar para si a tarefa de promovê-la (BRASIL, 1998, p. 25).

Com relação ao conteúdo, na produção de gêneros orais, os PCN (BRASIL, 1998, p. 58) incluem os recursos prosódicos como recursos técnicos para a apropriação e uso mais consciente e voluntário dos alunos, juntamente com recursos gestuais, semânticos e pragmáticos. Assim, valorizam a instrumentalização do aluno para melhorar seu desempenho em diversas interações orais públicas formais e não formais.

Sobre o tratamento didático dos conteúdos, os PCN propõem a construção de um corpus de textos orais com função modelizadora tanto para as atividades de escuta quanto de 
produção oral. Além disso, sugere algumas atividades a serem realizadas com o intuito de promover a capacidade de preparação prévia e correção simultânea da fala.

A entoação, especificamente, aparece implicitamente como "uso da linguagem característico do gênero" nas sugestões de atividade de escuta de texto oral. Na seção de produção do texto oral, a entoação aparece explicitamente somente como um recurso para leitura dramática. Nesta seção, o termo entoação aparece usado como prosódia, pois funciona como um termo amplo para indicar outras características da fala, como vemos na citação: "representação de textos teatrais ou de adaptações de outros gêneros, permitindo explorar, entre outros aspectos, o plano expressivo da própria entoação: tom de voz, ritmo, aceleração, timbre” (BRASIL, 1998, p. 75, grifo nosso).

Nos Guias do Programa Nacional do Livro Didático, em que o tratamento didático dado aos conteúdos previstos nos PCN é legitimado por meio de uma matriz de princípios e critérios de avaliação, há a resenha das coleções selecionadas para envio gratuito às escolas que fazem parte do Programa. Com relação ao Guia de língua portuguesa (BRASIL, 2013) para o ensino nos quatros anos finais do Ensino Fundamental, o Guia apresenta os parâmetros gerais de participação das coleções no Programa, incluindo as regras de exclusão, e também os parâmetros específicos da área de ensino.

O Guia do livro didático - PNLD 2014 (BRASIL, 2013) apresenta seis eixos principais de análise, a saber: a) leitura, que inclui o conjunto de textos das coleções e as atividades de exploração dos textos; b) produção de texto, atividades que visem o desenvolvimento da proficiência escrita; c) oralidade, que inclui a interação oral professoraluno, a relação com os sistemas de escrita e o uso público e formal da linguagem oral; d) conhecimentos linguísticos, em que se priorizam atividades que levem à reflexão sobre a língua e à análise sobre os fatos da língua; e) manual do professor, em que se avalia a adequação dos volumes com relação à linha pedagógica declarada e f) DVDs, que se referem ao projeto multimídia das coleções.

No documento citado, foram selecionadas 12 coleções para o uso nos anos finais do ensino fundamental. Na síntese do resultado de análise das mesmas, a oralidade figura como o eixo de ensino menos explorado:

Em relação aos demais eixos de ensino, o da oralidade ainda é o menos explorado, o que às vezes provoca algum desequilibrio da proposta pedagógica. Entretanto, assim como no Guia de 2011, todas as coleções tomam a oralidade como objeto de ensinoaprendizagem, não se restringindo a diferentes formas de mobilizá-la como atividade meio no trabalho com outros conteúdos. A articulação com a leitura está fortemente presente em propostas de encenação, declamação, oralização de texto escrito, etc. Mas nenhuma das coleções se restringe a esse tipo de abordagem; além disso, há orientações específicas para esses usos da linguagem oral. Além do mais, gêneros orais públicos e/ou tipicamente escolares, como o debate, a entrevista, a exposição oral, etc., são abordados em atividades que se organizam em sequências didáticas destinadas a explorar mais ou menos sistematicamente diferentes aspectos da produção oral. A escuta atenta e crítica ainda é pouco explorada (BRASIL, 2013, p. 27, grifo do autor). 
Observando as resenhas das 12 coleções selecionadas, notam-se diferenças de tratamento em cada uma delas. Em apenas sete das coleções avaliadas, há a menção a elementos e recursos linguísticos específicos da oralidade, em seis delas, a entoação ou o tom de voz aparecem como um recurso expressivo. O uso de material multimídia também é pouco utilizado com função modalizadora de gêneros orais formais, mas três coleções oferecem o recurso aos professores. Finalmente, há coleções que, segundo o Guia (BRASIL, 2013, p. 59-119), além de a oralidade ser pouco explorada em relação a outros eixos de ensino, ela também carece de atenção teórica e pedagógica. Em cinco dos livros analisados, há o comentário de que cabe ao professor ampliar o trabalho no eixo da oralidade, seja por haver poucas atividades sistematizadas, seja por falta de orientação suficiente no livro do aluno para propiciar o desenvolvimento de proficiência oral.

Com relação à análise de materiais didáticos de língua portuguesa e oralidade, é importante citar Marcuschi (2005) que, em consonância ao que já discutimos até o presente momento, destaca a ausência da oralidade nos materiais didáticos. $\mathrm{O}$ autor apresenta a visão de língua e de fala veiculada pelos materiais didáticos em geral e aponta para a necessidade de os materiais didáticos trabalharem com a oralidade de forma que os alunos possam usufruir dos recursos linguísticos disponíveis de maneira apropriada e produtiva. $\mathrm{O}$ autor apresenta algumas das razões para se ensinar oralidade: tratamento da variação, análise de níveis de língua, relação integrada com a escrita, contribuição da fala na formação cultural e na preservação de tradições não escritas (MARCUSCHI, 2005, p. 24-25).

Ao considerar os avanços teóricos na área do estudo do fenômeno oral, discorrendo sobre o ensino da oralidade, o teórico afirma:

É importante ter em mente que o ensino de língua na escola não visa a formar linguistas ou gramáticos e muito menos analistas da fala, analistas de texto ou da conversação. Tudo se resume a este objetivo: ensinar os alunos a perceberem a riqueza que envolve o uso efetivo da língua como um patrimônio maior do qual não podemos abrir mão. Pois, se há um estudo que vale a pena no ensino básico é o estudo da língua e suas possibilidades. A língua será a grande ferramenta diária da qual ninguém poderá abdicar durante toda sua vida, venha ele a fazer seja lá o que for. (MARCUSCHI, 2005, p. 32, grifo do autor).

Após as considerações sobre a oralidade nos documentos oficiais e no material didático, convém frisar o papel da entoação no ensino de língua materna. No final desta seção, elencamos, portanto, alguns pontos a serem analisados e pesquisados em futuros trabalhos para que se dê a efetiva relevância à entoação como um elemento da oralidade que pode ser trabalhado nos anos finais do ensino fundamental.

Partindo-se da seguinte questão: se o aluno já sabe falar, qual é a contribuição do estudo da entoação no ensino de língua portuguesa como língua materna? Considerando o quadro teórico linguístico de análise da entoação e a relevância de se estudar a modalidade oral da língua, destacamos que:

- o aluno adquire mais competência no uso do recurso linguístico da entoação ao ser exposto a seus usos e funções; 
- o aluno pode fazer uso consciente de alguns recursos linguísticos específicos da modalidade oral da língua;

- o aluno apreende e compreende a riqueza da variação da entoação com diversos propósitos em cada situação;

- amplia-se a capacidade de o aluno reconhecer intenções do autor de textos orais, por ser a entoação um dos elementos que possui, além da função sintática, funções semântica e pragmática.

Assim, é preciso olhar atentamente para os materiais didáticos disponíveis e analisá-los com o intuito de aprimorar o tratamento dado à oralidade. É preciso ainda, diante do exposto neste artigo, levantar elementos a serem desenvolvidos em sala de aula e, principalmente, propor atividades didáticas que propiciem o desenvolvimento da capacidade linguística dos alunos na apropriação de recursos linguísticos, como a entoação, para uso em diversas situações públicas e formais orais, nas quais um resultado positivo é dependente de desenvoltura linguística, tanto quanto à organização da informação, à forma de exposição, às estratégias de argumentação quanto à avaliação no uso dialetal e na adequação do registro.

\section{Considerações finais}

Neste artigo, a partir de uma leitura mais ampla da oralidade no ensino de língua, propusemos verificar como a entoação pode contribuir para a formação linguística do aluno das séries finais do ensino fundamental. Várias funções da entoação foram elencadas e foi possível notar que o conhecimento do recurso expressivo da entoação pode beneficiar o aluno em suas interações verbais orais em variadas situações de uso.

A constatação da necessidade de se abranger o estudo da língua na sua modalidade oral no ensino fundamental de forma sistematizada é um passo inicial para o desenvolvimento de descrições de gêneros orais e de desenhos de atividades didáticas sistematizadas que considerem a modalidade oral em sua estrutura e funcionamento único e não como uma modalidade a ser representada pela escrita. Dessa forma, o estudo de aspectos linguísticos inerentes à oralidade, como a entoação e outros aspectos prosódicos é necessário, juntamente, com o reconhecimento do funcionamento diversificado de outros aspectos linguísticos nas modalidades oral e escrita da língua, como elementos coesivos e argumentativos.

Vale ressaltar ainda que o foco nas atividades para a apropriação da entoação na sua diversidade não é o de ensinar o aluno a falar, mas de instrumentalizá-lo para usos apropriados e adequados a situações em que o texto oral é requerido para que o aluno tenha ampla oportunidade de expressão. Diante disso, há a necessidade de se desenhar atividades didáticas para o desenvolvimento de habilidades orais ao falante de língua materna em contextos em que o aluno não está acostumado na sua vida diária, contextos estes cuja performance linguística do indivíduo afeta diretamente os resultados alcançados: entrevista de emprego, exposições orais (briefing/vendas), etc. 
Sendo assim, é essencial que se desenvolvam mais estudos sobre o ensino de características entoacionais do português na sala de aula, com vistas a aprimorar os usos, em diferentes registros, da língua portuguesa em sua modalidade oral.

\section{REFERÊNCIAS}

BOLINGER, D. A theory of pitch accent in English. Word, New York, v. 14, n. 2-3, p. 109149, ago./dez. 1958.

BRASIL. Ministério da Educação, Secretaria de Educação Básica. Guia do Livro Didático: PNLD 2014: língua portuguesa: ensino fundamental: anos finais. Brasilia: MEC/SEB, 2013. 120 p. Disponível em: <http:/www.fnde.gov.br/programas/livro-didatico/guias-dopnld/item/4661-guia-pnld-2014>. Acesso em: 04 out. 2015. 119 p.

BRASIL. Ministério da Educação, Secretaria de Educação Fundamental. Parâmetros Curriculares Nacionais: terceiro e quarto ciclos do ensino fundamental: língua portuguesa. Brasilia: MEC/SEF, 1998. 106 p.

CAGLIARI, L. C. Prosódia: algumas funções dos supra-segmentos. Cadernos de Estudos Linguísticos. Campinas, n. 23, jul./dez. 1992. Disponível em: <http://revistas.iel.unicamp.br/index.php/cel/> . Acesso em: 20 ago. 2015. p. 137-151.

Elementos de fonética do Português Brasileiro. São Paulo: Paulistana, 2007. 194

p.

CÓRDULA, M. S. M. Entoação e sentidos: análise fonético-fonológica dos padrões entoacionais do português brasileiro e do inglês norte-americano no filme Shrek (2001). São Paulo: Cultura acadêmica, 2013. Disponível em: 〈www.culturaacademica.com.br〉. Acesso em: 04 out. 2015. 296 p. E-book.

COUPER-KUHLEN, E. An introduction to English prosody. London: Edward Arnold, 1986. $224 \mathrm{p}$.

HALLIDAY, M. A. K. The tones of English. In: Studies in English Language.

Editado por: Jonathan J. Webster. London: Continuum, 2005. v. 7, cap. 8, p. 237-263. (Collected works of M. A. K. Halliday).

A course in spoken English: Intonation. London: Oxford University Press, 1970. $142 \mathrm{p}$.

HALLIDAY, M. A. K.; GREAVES, W. S. Intonation in the grammar of English. London: Equinox Publishing Ltd., 2008. 224 p.

LADD, D. R. Intonational Phonology. 2. ed. New York: Cambridge University Press, 2008. (Cambridge Studies in Linguistics, 79). E-book.

LADEFOGED, P. A course in phonetics. 5. ed. Boston, MA: Thomson Wadsworth, 2006. $310 \mathrm{p}$.

LAVER, J. Principles of phonetics. Cambridge: Cambridge University Press, 1994. 736 p.

LEHISTE, I. Suprasegmentals. Cambridge, MA: The MIT Press, 1970. 194 p. 
LIBERMAN, M. Y. The intonation system of English. 1975. 319 f. Thesis (Doctor of Philosophy) - Massachussets Institute of Technology, Boston, 1975.

MARCUSCHI, L. A. Oralidade e ensino de língua: uma questão pouco falada. In: DIONÍSIO, A. P.; BEZERRA, M. A. (orgs.). O livro didático de português: múltiplos olhares. 3. ed. Rio de Janeiro: Lucerna, 2005. p. 21-34.

MASSINI-CAGLIARI, G.; CAGLIARI, L. C. Fonética. In: MUSSALIM, F.; BENTES, A. C. (Org.). Introdução à Linguística: domínios e fronteiras. 6. ed. São Paulo: Cortez, 2006. v. 1 , cap. 3, p.106-146.

O' CONNOR, J. D.; ARNOLD, G. F. Intonation of colloquial English: a practical handbook. London: Longman, 1961. 304 p.

PALMER, H. E. English intonation: with systematic exercises. Cambridge: Heffer, 1922. $134 \mathrm{p}$.

PIERREHUMBERT, J. B. The Phonology and phonetics of English intonation. 1980. Thesis (Doctor of Philosophy) - Harvard University, Harvard, 1980. 401 p.

PIKE, K. L. The intonation of American English. Ann Arbor: The University of Michigan Press, 1945. 200 p.

Recebido em: 05/10/2015

Aprovado em: 07/07/2016 